made on the operator should be done while he is in actual control of his vehicle. We realize that this may frequently present practical difficulties, but feel that the phenomenon would be much better demonstrated under these conditions.

JuLIAN LeFr.

The Maudsley Hospital,

Denmark Hill, London, S.E.5.

Sociological Research Unit,

ANDREW SzmmLA.

University College,

Gower Street, London, W.C.r.

\section{THE ORACLE OF TROPHONIUS}

Dear Sir,

Professor Kouretas's article (Joumal, December, 1967 , pp. $144^{1-1446)}$ is to be welcomed since it focuses on a very important field. It would seem helpful, without entering the larger "problems of religions", to clarify the practices which aided men to come to terms with their biological endowments and individual crises, their social heritage and the hardships of existence. The "reification and deification" which resulted in the Greek pantheon will probably repay intensive study such as has been given the other legacies of this period.

Although Professor Kouretas avoids the sin of patronizing the ancients, he misses important aspects of the material he presents. This error is probably due to his adherence to certain modern theories. He draws an analogy between ancient practices and modern techniques and concludes only that they share psychodynamic theory. The comparison with drug treatment is missed.

From the evidence that Professor Kouretas adduces, there was "shock treatment" by the use of hallucinogens. There was "sensory deprivation" in the sense of varying loss of contact with a shared or social world. This too seems largely the result of the drugs.

Timarchus's "magnificent journey through the Universe" and "the underground trip" can be directly compared to "the Trip" of modern days. When under the influence of such drugs the individual is now said to be "high". With the Greeks, although the drugs were in the context of a complex social ritual, their use was described as resulting in a "descent".

B. BARNETT.

2 Belle Walk,

Birmingham, 13.

Dear Sir,

The excellent historical interpretation of the significance of "The Oracle of Trophonius" by
Professor Kouretas refers to suggestion but omits all reference to hypnosis. The suppliant, garlanded as a sacrificial victim, in tight clothes and heavy boots, was purified, drank the waters of Forgetfulness and Memory, and prayed to the wonder-working statue. Arms fixed, carrying the offering of barley cakes, now lying prone, he is torpedoed through a narrow opening into a cave of oppressive darkness.

The fretful infant is rocked to sleep, with decreasing rhythms and the lullaby that ceases before the rocking. Alternatively, the child is raised, clothes tightened firmly inhibiting movement, and, as suddenly, inverted. Light is changed to darkness, with parting shots of "Quiet! Hush! Sleep!". Disturbances of the organs of balance, encircling "mystic" passes, deliberate pressures on carotid sinus, "whiplash" effects, changing intense light to felt oppressive darkness are the mechanics of the hypnotist utilizing mechanical agitation of the brain. Changes of proprioceptivity, exteroceptivity and afferent stimulation lead to suspension of cerebral activity.

The worship of Trophonius was Dionysiac, orgiastic, ecstatic, whereby each devotee could become god. Plutarch describes Timarchus experiencing such transcendental mysticism. Rituals are magical processes explained by mythology. The oracle of Gaia, the Earth Mother, aroused awesome dread, through the mythical guardian, Python.

Apollo had his dreaded Erinnyes, that "bow the heart, bend and break ... and pierces its way through the murderer, breeding diseases that none may allay" (Aeschylus, Choephorae, 64). Heraclitus (c. 500) described the Sibyl of the Cumaean oracle "raving lips uttering things mirthless, unadorned and unscented, reaches over two thousand years", and Plato (Phaedrus 244) "... and the priestesses ... when out of their senses have conferred great benefits on Hellas, both in public and private life, but when in their senses few or none". For at Delphi it was the priestess not the suppliant who chewed laurel (cyanide) or was "overcome" by mephitic vapours, yet healing resulted. Belief and expectancy of both healer and sufferer are the vital factors.

The initiate gives up his present position in society, is segregated for stoical training and reintegrates with advanced status. Society uses criteria of sex, age, class and aptitudes for these rituals. Weaning processes rather than feeding, maturation rather than regression, are emphasized.

The Laws of magical healing are comparable, and Charcot ("The Faith Cure", New Review, London, 1893) pointed out the similarity of sitings and routines of ancient temples and modern shrines. There is the preparatory stage of the sufferer leaving his home, undertaking an arduous journey, with 
hope increasing as the goal is neared. A probationary educative period, with interviews, sermons, prayers, bathings, purifications, offerings, drinking of healing waters, thwarting, fatiguing the patient initiate, until criticism becomes inhibited and suggestibility increases.

Finally, he enters the inner taboo sanctum, sees the sacra and touches the wonder-working statue, conjoins the totem, becomes revitalized, not only to recovery, but a rebirth with a new spirit. The sick man, the previous burden of his family, now possessed of the divine spirit, sees himself and is regarded with awe and admiration. The commemorative tablets round temple entrances extolled the virtues of the healed sick as much as the gods.

The two wells, Lethe and Mnesomyne, Forgetting and Remembering, are mentioned in the Orphic and Petelia tablets, advising conduct for immortality.

"Thou shalt find on the left of the House of Hades a

And by the side thereof standing a white cypress. Well-spring, To this Well-spring approach not near. But thou shalt find another by the Lake of Memory, Cold water flowing forth, and there are Guardians before

J. Harrison. Prolegomena to the Study of Greek Religion.

The recall of memories lies at the root of all insight therapies while "abreaction" techniques seek their re-experience. Contrariwise, "forget the past" was utilized in exhortations by mesmerists, repression encouraged, suggestion that experienced symptoms disappear. Hypno-analysis utilizes both evocation and suppression.

Orpheus modified Dionysiac worship, and saw Eros, Love, as the source of all things. Man, to overcome evil within himself, must lead the life of asceticism to achieve divinity. Cycles of reincarnation were avoided through initiations, learning magic formulae, drinking of waters, food abstinences, penances and purgations.

"What have I done amiss? What of right accomplished? What that I ought to have done have I omitted to do?" sang Pythagoras. (Diog. Laërt. Vit. Pyth. xix.)

As Dionysus had his "reincarnation" in Mesmer so Orpheus returned in Freud, and many strive to become the new Asclepius healing through the dream, sleep, drugs and painful electrical conditionings.

Professor Kouretas compares the "unconsciousness" of the devotee, and his "impairment of memory" with that induced physically by insulin coma or electric shock.

In Samuel ii, vi, 4-7, we read of Uzzah springing forth to prevent the Ark of the Law from falling to the ground. As he touched the Ark he was struck dead for his sin. The Ark was taboo, he was not of the priesthood, and violation brought the penalty of death. Therefore, totem and taboo equate, in the only certainty of the effect on the human body of electricity, that at given intensities it most certainly causes death.

"Cray Hill", Rectory Lane,

L. A. Nichors. 